\title{
Corpo e tecnologia: um estudo das redes sociais na Web
}

\author{
Patrícia B. Scherer Bassani, Feevale, patriciab@feevale.br \\ Regina de Oliveira Heidrich, Feevale, rheidrich@feevale.br
}

Resumo: A partir dos estudos Rheingold (1996), Castells (2003), Recuero (2005) e Lemos (2007), as redes sociais na Web são entendidas como sistemas fundamentados na interação social, constituindo novas formas de sociabilidade. Este trabalho aborda um estudo comparativo entre três redes sociais na Web, buscando identificar as diferentes propostas, especialmente em relação a representação do sujeito, recursos de comunicação e formação de redes. O presente estudo constitui uma primeira etapa de pesquisa, que busca investigar o potencial das redes sociais na Web como espaços de inclusão de pessoas com deficiência.

Palavras-chave: redes sociais, comunidade virtual, inclusão

Title: Body and technology: a study about social networks

Abstract: Social networks has recently emerged as an important interdisciplinary research area. Many researchers (Rheingold, 1996, Castells, 2003, Recuero, 2005, Lemos 2007) have been studying about social networks and suggested that these systems are based in social interaction, performing different kinds of sociability. This paper explores a comparative study among tree social networks, in order to understand social issues and also explore how these social networks can be used for desability people.

Keywords: social networks, virtual community, inclusion

\section{Introdução}

Estudos contemporâneos na área da Cibercultura $^{1}$ (Lemos, 2007, Lévy, 1999), apresentam uma nova perspectiva de compreensão da relação entre corpo e tecnologia. Enquanto na "vida real" o corpo determina a identidade e as formas de socialização, no ciberespaço ${ }^{2}$ a identidade é ambígua, sem certezas em relação a gênero, raça, idade e, assim, possibilita novas formas de sociabilidade.

No espaço virtual, o corpo desaparece, dando lugar a espectros que circulam como informações e, assim, "livre de todos os constrangimentos físicos, o corpo tornase puro símbolo digital" (Lemos, 2007, p. 174).

Destaca-se que o termo "virtual" pode ser entendido a partir de três diferentes perspectivas. Comumente, o termo faz referência ao que não é real, aquilo que não existe em termos físicos; também remete à questões técnicas, especialmente relacionado a área da informática. Entretanto, pode ser entendido a partir de uma perspectiva filosófica, onde virtual significa algo que existe em potência e não em ato e, assim, o

\footnotetext{
${ }^{1}$ Cibercultura é apresentada como uma marca da cultura contemporânea, cujo imaginário e práticas convergem para uma relação mais intensa entre homens e máquinas, sugerindo novos hábitos cotidianos e novas formas de socialização através da comunicação mediada por computador (Lévy, 1999, Lemos, 2007).

2 Conforme Lévy (1999), o ciberespaço, também chamado de "rede", é "o novo meio de comunicação que surge da interconexão mundial dos computadores. O termo especifica não apenas a infra-estrutura material da comunicação digital, mas também o universo oceânico de informações que ela abriga, assim como os seres humanos que navegam e alimentam este universo" (p. 17)
} 
virtual não se opõe ao real, mas ao atual, levando-se em conta a possibilidade de desterritorialidade (Lévy, 1999). Esta questão implica na compreensão de que uma informação na Web está fisicamente disponível em algum lugar (computador, servidor), mas virtualmente presente em cada ponto da rede onde for solicitada.

O computador é, portanto, um operador de potencialização da informação. Dito de outro modo: a partir de um estoque de dados iniciais, de um modelo ou de um metatexto, um programa pode calcular um número indefinido de diferentes manifestações visíveis, audíveis e tangíveis, em função da situação em curso ou da demanda dos usuários. $\mathrm{Na}$ verdade, é somente na tela, ou em outros dispositivos interativos, que o leitor encontra a nova plasticidade do texto ou da imagem, uma vez que o texto em papel (ou o filme em película) já está realizado por completo. A tela informática é uma nova "máquina de ler", o lugar onde uma reserva de informação possível vem se realizar por seleção, aqui e agora, para um leitor particular. Toda leitura em computador é uma edição, uma montagem singular (Lévy, 1996). O autor destaca, ainda, que considerar o computador apenas como um instrumento para produzir textos, sons ou imagens sobre suporte fixo (papel, película, fita magnética) equivale a negar sua fecundidade propriamente cultural, ou seja, o aparecimento de novos gêneros ligados à interatividade.

Desta forma, considerando-se que nos espaços virtuais o corpo físico não é mais determinante da identidade e que as tecnologias da informação e comunicação (TICs), especialmente o computador, oportunizam diferentes formas de interação, participação e socialização, este trabalho apresenta uma análise de diferentes redes sociais disponíveis na Web. As redes sociais, entendidas como novos espaços de interação, potencializam diferentes formas de sociabilidade. Entende-se que a compreensão da dinâmica das redes sociais pode orientar novos estudos enfocando sua utilização como espaço de inclusão para pessoas com deficiência.

\section{Redes sociais e comunidades virtuais}

Conforme Rheingold (1996), "a rede" é o termo informal que designa as redes de computadores interligadas, empregando a tecnologia de comunicação mediada por computador (CMC), a fim de associar pessoas de todo o mundo na forma de debates públicos. $\mathrm{O}$ autor aponta que a $\mathrm{CMC}$ tem potencial para mudar a vidas das pessoas em três níveis distintos, mas fortemente interdependentes. Primeiramente, como sujeitos, uma vez que percepções, pensamentos e personalidades podem ser afetadas pelo modo como é usado o meio de comunicação e vice-versa. $\mathrm{O}$ autor considera este nível fundamental, pois a CMC "apelam a certas necessidades intelectuais, materiais e emocionais que sentimos enquanto organismos vivos que somos" (p. 26). O segundo nível compreende as relações interpessoais, amizades e comunidades; a CMC possibilita novas capacidades de comunicação multilateral (muitos para muitos). O terceiro nível, o nível político, deriva do anterior, caracterizado pelas relações sociais e, assim, o autor entende que "a relevância política da CMC resulta da sua capacidade para desafiar o monopólio dos poderosos meios de comunicação detidos pela hierarquia política e talvez assim revitalizar a democracia dos cidadãos" (p. 28).

Alava (2002), aponta que a “ (...) a tecnologia das redes determina uma profunda mudança das relações sociais, assim como a organização de inúmeras atividades humanas. Tal evolução poderia levar a mecanismos de partilha, de colaboração, de gestão coletiva e de cognição distribuída" (p. 47). 
Também Castells (2003) aponta que a "grande transformação da sociabilidade em sociedades complexas ocorreu com a substituição de comunidades espaciais por redes como formas fundamentais de sociabilidade" (p. 107).

Para Recuero (2005), as redes sociais são entendidas como sistemas fundamentados na interação social, buscando a conexão e comunicação entre diferentes sujeitos.

Castells (2003) destaca o deslocamento da comunidade para a rede, como forma central de organizar a interação. Assim, as redes sociais vêm incorporando as comunidades virtuais e a Internet caracteriza-se como uma "nova" forma de organizar a interação.

As comunidades virtuais são entendidas como "agregados sociais surgidos na Rede, quando os intervenientes de um debate o levam por diante em número e sentimento suficientes para formarem teias de relações sociais no ciberespaço" (Rheingold, 1996, p. 18).

Castells (2003) apresenta a noção de "comunidades virtuais", como novos suportes tecnológicos para a sociabilidade, diferentes de outras formas de interação, mas não inferiores. Também destaca o fato de que "é a crescente diversidade dos padrões de sociabilidade que constitui a especificidade da evolução social em nossas sociedades" (p.106). E assim, aponta que "o decisivo, portanto, é a passagem da limitação espacial como fonte de sociabilidade para a comunidade espacial como expressão de organização social" (p. 106). Destaca, também, que as comunidades virtuais trabalham com base em duas características fundamentais comuns:

a) valor da comunicação livre, horizontal, caracterizada pela comunicação online de muitos para muitos;

b) formação autônoma de redes, que envolve a possibilidade de qualquer pessoa escolher/definir os fluxos de navegação na rede, além do potencial de criar e divulgar suas próprias informações, induzindo a formação de uma rede.

E assim, a comunidade virtual possibilita que cada sujeito seja, simultaneamente, autor, audiência e argumentista.

Nesta perspectiva, percebe-se que a possibilidade de pertença a uma comunidade (ou várias) sem a necessidade de deslocamento físico, amplia as oportunidades de participação para sujeitos com diferentes necessidades, sejam elas físicas ou cognitivas, transitórias ou permanentes. Além disso, "como não podemos ver-nos uns aos outros no ciberespaço, o sexo, a idade, nacionalidade e aspecto físico não transparecem, a menos que pretendamos tornar públicas essas características" (Rheingold, 1996, p.43). E assim, "quem tem dificuldades em fazer novas amizades devido a deficiências físicas descobre que nas comunidades virtuais é tratado como sempre desejou - como ser racional, transmissor de idéias e sentimentos, e não como um recipiente carnal com determinada aparência, andar ou falar (ou mesmo sem andar ou falar)" (p. 43).

Existem diversos ambientes na Web para oportunizar a constituição das redes sociais. Assim, após o levantamento teórico incial sobre a conceituação e caracterização de redes sociais, a segunda etapa deste estudo envolveu a pesquisa e participação em algumas destas redes, a fim de identificar características e especificidades.

\section{Redes sociais na Web}

Para fins deste estudo foram analisados 3 (três) ambientes/redes sociais na Web (Orkut, Sônico, Hi5), direcionados para adultos, a fim de investigar similaridades e diferenças. 
Os ambientes foram escolhidos a partir de dois critérios: disponibilidade em língua portuguesa e número de usuários no Brasil ${ }^{3}$.

A partir do referencial teórico estudado (Lemos, 2007, Rheingold, 1996, Castells, 2003, Recuero, 2005), foram definidos 3 (três) critérios para a análise:

a) representação do sujeito: envolve as ferramentas que possibilitam ao sujeito a construção de seu perfil, a disponibilização de sua identidade na rede;

b) recursos de comunicação: identificação das ferramentas que permitem a comunicação e interação entre os diferentes sujeitos participantes do ambiente;

c) formação de redes: possibilidade que o ambiente oferece para o envolvimento em redes e participação em comunidades virtuais.

Segue a análise de cada um dos ambientes, balizadas pelos critérios acima apresentados.

\subsection{Orkut}

O Orkut ${ }^{4}$ é uma rede social (social network), também conhecida como rede de relacionamentos na Internet, voltada ao público adulto, filiada à empresa Google. A análise realizada apontou as seguintes características:

a) representação do sujeito: usuários cadastrados no ambiente podem construir um perfil, classificado em geral (dados de identificação), social (relacionado a preferências pessoais, como estilos musicais favoritos, filmes, opinião política, opção sexual, e outros), contato (telefone, e-mail, endereço), profissional (escolaridade e dados profissionais) e pessoal (informações sobre aparência pessoal e relacionamentos) . O ambiente também disponibiliza ao usuário um álbum de fotos. Interessante destacar que existe uma seção chamada "Depoimentos", onde os outros (amigos) podem deixar registradas suas impressões sobre o perfil do sujeito. Também se pode classificar o outro em quatro categorias: confiabilidade, lealdade, aparência (sexy), além da possibilidade de indicar que se é fã de algum amigo;

b) recursos de comunicação: os sujeitos cadastrados no ambiente podem se comunicar a partir do envio e recebimento de mensagens, na ferramenta scrapbook (livro de recados); também existe a possibilidade de editar um comentário, que fica disponível na página do perfil. Outro recurso interessante de comunicação, que explora recursos visuais, são os diferentes aplicativos disponíveis, como o BuddyPoke, que permite expressão de sentimentos por meio da representação de avatares ${ }^{5}$.

c) formação de redes: o Orkut dispõe de um sistema que permite ao sujeito, partindo de sua página principal, acessar perfis de amigos e, a partir daí, de amigos de amigos. Permite a verificação do conteúdo das comunidades nas quais está envolvido e, clicando nelas, navegar por comunidades semelhantes, e assim por diante. Assim, "a partir de sua área pessoal, o usuário pode realizar algumas ações básicas, como identificar outros usuários que são seus amigos (e que passam a constar como friends em sua página). Os amigos de um indivíduo cadastrado formam a sua rede e assim um usuário pode ligar-se a milhares de pessoas através de threads (ou teias), ou seja, cadeias que envolvem amigos de amigos e assim por diante"(Fontanella, Prysthon, 2004).

\footnotetext{
${ }^{3}$ Conforme o mecanismo de pesquisa Alexa (www.alexa.com), que disponibiliza as estatísticas da audiência na Web, os ambientes selecionados nesta pesquisa constam na lista dos Top 100 Brasil, conforme acesso em 22/10/2008: Orkut, $2^{\mathrm{a}}$ posição; Sonico, $34^{\mathrm{a}}$ posição; Hi5, $86^{\mathrm{a}}$ posição.

${ }^{4}$ http://www.orkut.com

${ }^{5}$ Em um mundo virtual, cada sujeito é representado por um avatar, que é um personagem criado e controlado pelo criador.
} 
Cada sujeito cadastrado pode fazer parte e/ou criar comunidades temáticas onde podem ser promovidos debates, troca de idéias e informações, além da possibilidade de conhecer outras pessoas com interesses semelhantes.

Outra característica interessante do ambiente é a possibilidade de articulação da página principal (perfil do usuário) a outros ambientes. Assim, é possível ao usuários compartilhar links para blogs, fotologs e outros ambientes de sua autoria.

\subsection{Sônico}

O Sônico ${ }^{6}$ é uma rede de relacionamentos que pretende suprir os problemas das outras redes tais como usuários falsos e spams. Conforme informações disponíveis no ambiente, o Sônico tem por objetivo oferecer um conjunto de aplicações sociais, que permitem o relacionamento e o reencontro com pessoas conhecidas, com segurança, privacidade e ordem. É voltado para o público adulto.

Inicialmente em língua espanhola e locado em Buenos Aires, o ambiente Sônico foi inaugurado em agosto de 2007 e já possui milhares de usuários ativos registrados no Brasil e em países da América Latina. A rede também possui presença relevante na Espanha e apresenta as seguintes características:

a) representação do sujeito: assim como o Orkut, o Sônico também disponibiliza opções de perfil, fotos, vídeos, sugerindo que o usuário disponibilize sua fotografia. Entretanto, apresenta alguns diferenciais, como a possibilidade de escolha da interface, disponibilizando diferentes temáticas de cores e estilos e um álbum de fotos ilimitado;

b) recursos de comunicação: permite a comunicação síncrona, disponibilizando um comunicador de mensagens instantâneo (messenger) e assíncrona, a partir do envio de recados;

c) formação de redes: permite a criação de redes de amigos e o envolvimento em comunidades. Também existe a possibilidade de importar contatos de outras redes sociais e serviços de portais populares.

\subsection{Hi5}

O ambiente $\mathrm{Hi}^{7}$ está disponível para diversos países e foi lançado em 2003. Foi desenvolvido por uma companhia privada, sediada em São Francisco, Califórnia.

Conforme informações disponíveis no site, a equipe tem como objetivo disponibilizar o ambiente em diferentes linguagens. A meta é que até o final de 2008 esteja disponível em 65 línguas diferentes. Apresenta as seguintes características:

a) representação do sujeito: assim como os demais ambientes analisados, permite inserção de fotografia, configuração de dados pessoais, configuração de privacidade, onde o usuário seleciona o que é público ou o que deve ser disponibilizado apenas para os amigos. Assim como o Sônico, permite estilizar a página de perfil, a partir da disponibilização de diferentes interfaces. O ambiente permite que o usuário "dê um five" a um amigo, ou seja, uma forma divertida de caracterizar o outro, ou o relacionamento com o outro (por exemplo: campeão, legal, bonitinho, melhor amigo e outros);

b) recursos de comunicação: disponibiliza espaço para que os amigos possam postar comentários sobre o sujeito; permite o envio e recebimento de mensagens, mantendo um correio interno (armazena as mensagens recebidas e as enviadas). Um

\footnotetext{
${ }^{6}$ http://www.sonico.com

7 http://www.hi5.com
}

V. 6 No 2, Dezembro, 2008 
recurso diferenciado é o diário, ferramenta que permite a entrada de registros associadas (ou não) a fotografias;

c) formação de redes: permite a criação de redes de amigos; possibilita a criação de comunidades virtuais, a partir da ferramenta Grupos (os usuários podem criar e/ou participar de grupos).

\section{Discussão dos resultados}

Conforme Recuero (2006), as redes sociais na Internet "são as redes de atores formadas pela interação social mediada pelo computador" (p. 14). Assim, a autora define uma rede social como um conjunto de dois elementos: os atores (pessoas, instituições ou grupos; os nós da rede) e suas conexões (interações ou laços sociais). Nesta perspectiva, a percepção do Outro é essencial para a interação humana.

A participação inicial numa rede de relacionamentos implica na identificação do perfil do sujeito participante. Assim, este sujeito é convidado a uma reflexão sobre si mesmo: quem sou eu, do que gosto, preferências, como me vejo e, como dito anteriormente, os espaços virtuais permitem múltiplas identidades. Entretanto este potencial de ocultamento da real identidade desvela um conjunto de potencialidades e limitações destes ambientes. Se por um lado permite a livre identificação do sujeito, desvinculando-o do corpo físico, por outro lado pode-se investigar também se isto não remete a uma falsa sensação de pertencimento. Interessante também observar que Rheingold (1996) destaca que estes espaços caracterizam-se como "um local onde as pessoas acabarão frequentemente por se revelar mais intimamente do que estariam dispostas a fazê-lo sem a intermediação de telas e pseudônimos" (p. 44).

Nos ambientes analisados, a identificação detalhada do perfil é contemplada de formas diferenciadas. As redes sociais Orkut, Sônico e Hi5 possuem ferramentas que possibilitam a representação do sujeito a partir de um ponto de vista pessoal e também sob o ponto de vista do outro (amigo).

Nos encontros presenciais o outro é apresentado como uma presença viva, compartilhada pelos envolvidos, resultando num contínuo intercâmbio de expressividade, em que a subjetividade do outro torna-se disponível por uma série de indícios como olhares e gestos. Nesses encontros pode-se perceber contradições entre as características pessoais do outro e seus atos e/ou atitudes, sendo estas evidências mais facilmente ignoráveis na ausência física. Por outro lado, Recuero (2006) destaca os estudos de Judith Donath (1999), apontando que no ciberespaço, pela ausência de informações que geralmente permeiam a comunicação face-a-face, as pessoas são julgadas e percebidas por suas palavras (Donath apud Recuero, 2006, p. 63). Sob este ponto de vista, Rheingold (1996) ressalta que “(...) as palavras numa tela podem magoar. Embora a conversa online tenha o mesmo sabor efêmero e informal de uma conversa telefônica, tem o alcance e a perenidade de uma publicação" (p. 56). Também destacam-se os estudos de Boyd (2002) "explicando que as construções de identidade são representações do eu no ciberespaço. É preciso, assim, colocar rostos, informações que gerem individualidade e empatia, na informação geralmente anônima do ciberespaço" (Boyd apud Recuero, 2006, p. 63). Assim, em todos ambientes pesquisados, o sujeito é representado por uma imagem (normalmente sua fotografia). Além disso, todos ambientes disponibilizam espaço para divulgação de fotos.

As redes sociais na Web estimulam as relações entre os diferentes sujeitos a partir de diferentes mecanismos/ferramentas de comunicação síncrona e/ou assíncrona. $\mathrm{Na}$ verdade, é por meio destas trocas, provenientes de processos de comunicação, que surgem as comunidades virtuais. Os ambientes analisados disponibilizam diferentes 
ferramentas de interação e comunicação, e todos possuem espaço para a troca de mensagens. Estas mensagens podem ser em formato texto ou animação. Conforme dito anteriormente, o Hi5 disponibiliza um espaço de interação chamado Diário, que pode ser entendido como um blog pessoal articulado no próprio ambiente. Por outro lado, o Orkut permite disponibilizar um link para o blog pessoal desenvolvido em ambiente externo à rede social. Assim, as redes sociais possibilitam diferentes tipos de interação um-para-um ou um-para-muitos.

Interessante destacar os estudos de Castells (2003), no que se refere a formação de redes. Conforme o autor, a melhor maneira de compreender a constituição de comunidades online "é vê-las como redes de sociabilidade com geometria variável e composição cambiante, segundo a evolução dos interesses dos atores sociais e a forma da própria rede" (p. 109). Assim, nos ambientes analisados, os sujeitos têm a liberdade de criar suas redes de amigos e decidir quais comunidades virtuais têm interesse em participar. Além disso, os sujeitos podem criar suas próprias comunidades virtuais, (comunidades personalizadas). Nesta perspectiva, a rede se constitui a partir das relações (conexões) entre os atores (sujeitos), no espaço virtual. Conforme Castells (2003), "as comunidades on-line são, em geral, efêmeras e raramente articulam a interação on-line com a interação física" (p. 109).

\section{Considerações finais}

Este trabalho constitui uma primeira etapa de pesquisa que busca investigar o potencial das redes sociais como espaços de inclusão de pessoas com deficiência. As redes virtuais possibilitam diferentes recursos de comunicação, síncrona ou assíncrona, permitindo aos sujeitos envolvidos o contato contínuo com a rede de amigos, sem, entretanto, existir a necessidade da mobilidade física. Assim, se apresentam como grande possibilidade de inserção de pessoas com deficiência, diminuindo as dificuldades relativas à comunicação. Cabe destacar que as limitações de acesso a escrita no computador podem ser minimizadas em função de diferentes tecnologias assistivas, como mouses especiais e teclado virtual, permitindo uma utilização autônoma do computador.

Conforme dito anteriormente, as comunidades virtuais constituem diferentes suportes tecnológicos para a sociabilidade, diferentes de outras formas de interação, mas não inferiores. Nesta perspectiva, assim como aponta Recuero (2006, p. 135), "não se pode reduzir a interação unicamente ao ciberespaço, ou ao meio de interação. A comunicação mediada por computador corresponde a uma forma prática e muito utilizada para estabelecer laços sociais, mas isso não quer dizer necessariamente que tais laços sejam unicamente mantidos no ciberespaço". Entretanto, o ciberespaço, por suas características, permite a participação/envolvimento de diferentes públicos, além de possibilitar a manutenção de laços de amizade.

A formação de redes, especialmente o envolvimento em comunidades virtuais, possibilita o desenvolvimento uma postura colaborativa. Maraschin (2005) sustenta a idéia de que as "redes conversacionais suportadas por TIC possam facilitar interações de reconhecimentos e convivências com modos de viver e pensar distintos dos tomados como próprios, ampliando a possibilidade de produção de deslocamentos dos pontos de vista dos participantes" (p. 135).

Assim, entende-se que as tecnologias de informação e comunicação vêm se tornando, de forma crescente, importantes instrumentos de nossa cultura e, sua utilização, um meio concreto de inclusão e interação no mundo (Lévy, 1999). 


\section{Referências}

Castells, Manuel. A galáxia da Internet. Rio de Janeiro: Jorge Zahar, 2003.

Fontanella, F.I.; Prysthon, N.F.. Trocando figurinhas: sobre Orkut, frivolidades, neotribalismo e flanêrie. In: Congresso Brasileiro de Ciências da Comunicação, 27. 2004. Porto Alegre. Anais. São Paulo: Intercom, 2004. CD-ROM.

Lemos, André. Cibercultura: tecnologia e vida social na cultura contemporânea. 3 ed. Porto Alegre: Sulina, 2007.

Lévy, Pierre. O que é virtual? São Paulo: Editora 34, 1996.

Lévy, Pierre. Cibercultura. São Paulo: 34, 1999.

Recuero, Raquel. Comunidades Virtuais em Redes Sociais na Internet: Uma proposta de estudo. In: Ecompos, Internet, v. 4, n. Dez 2005, 2005.

Recuero, Raquel. Comunidades virtuais em redes sociais na internet: proposta de tipologia baseada no fotolog.com. Tese (doutorado) - Faculdade de Biblioteconomia e Comunicação, Programa de Pós-Graduação em Comunicação e Informação, Porto Alegre, 2006.

Rheingold, Howard. A comunidade virtual. Lisboa: Gradiva Publicações, 1996. 